\title{
Correction to: Assessment of HIF-1a expression and release following endothelial injury in-vitro and in-vivo
}

\author{
Lamia Heikal ${ }^{1,3}$, Pietro Ghezzi ${ }^{1}$, Manuela Mengozzi ${ }^{1}$ and Gordon Ferns ${ }^{1,2^{*}}$
}

\section{Correction to: Mol Med (2018) 24:22}

https://doi.org/10.1186/s10020-018-0026-5

Following publication of the original article (Heikal et al. 2018), the author Lamia Heikal would like to update her affiliation by adding a new one. The updated author affiliation is shown in this erratum.

Correct:

${ }^{1}$ Brighton and Sussex Medical School Department of Clinical and experimental investigation, University of Sussex, Falmer East Sussex, Brighton BN1 9PS, UK

${ }^{3}$ Department of Pharmaceutics, Faculty of Pharmacy, Alexandria University, Alexandria, 21521, Egypt

\section{Author details}

'Brighton and Sussex Medical School Department of Clinical and

Experimental Investigation, University of Sussex, Falmer East Sussex, Brighton

BN1 9PS, UK. ${ }^{2}$ Brighton and Sussex Medical School Department of Medical

Education, Mayfield House, Falmer East Sussex, Brighton BN1 9PH, UK.

${ }^{3}$ Department of Pharmaceutics, Faculty of Pharmacy, Alexandria University,

Alexandria 21521, Egypt.

Published online: 25 June 2020

\section{Reference}

Heikal, et al. Assessment of HIF-1a expression and release following endothelial injury in-vitro and in-vivo. Mol Med. 2018;24:22. https://doi.org/10.1186/ s10020-018-0026-5.

* Correspondence: G.Ferns@bsms.ac.uk

${ }^{1}$ Brighton and Sussex Medical School Department of Clinical and

Experimental Investigation, University of Sussex, Falmer East Sussex, Brighton

BN1 9PS, UK

${ }^{2}$ Brighton and Sussex Medical School Department of Medical Education,

Mayfield House, Falmer East Sussex, Brighton BN1 9PH, UK

Full list of author information is available at the end of the article

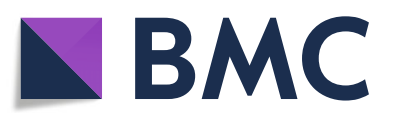

(c) The Author(s). 2020 Open Access This article is licensed under a Creative Commons Attribution 4.0 International License, which permits use, sharing, adaptation, distribution and reproduction in any medium or format, as long as you give appropriate credit to the original author(s) and the source, provide a link to the Creative Commons licence, and indicate if changes were made. The images or other third party material in this article are included in the article's Creative Commons licence, unless indicated otherwise in a credit line to the material. If material is not included in the article's Creative Commons licence and your intended use is not permitted by statutory regulation or exceeds the permitted use, you will need to obtain permission directly from the copyright holder. To view a copy of this licence, visit http://creativecommons.org/licenses/by/4.0/. 